\title{
The Correlation between Dative Constructions and Locative Constructions
}

\author{
Park Hyo Won \\ Pusan National University, Republic of Korea
}

\section{Introduction}

Locative Constructions and Dative Constructions have been regarded as third sentence type because of linar similarity. That is, the verb is followed by direct object and direct object is followed by prepositional phrase. However, when seen in light of argument structure, both determiner phrase following the verb and prepositional phrase following determiner phrase can be considered as argument in dative constructions. Yet, in locative constructions, only determiner phrase can be viewed as argument. Therefore, there are some assertions that argue the two constructions are different constructions. Nevertheless, this paper is based on the thought that the two constructions are similar constructions. Also, this paper will find some similarities between the two constructions in terms of syntactic and semantic aspects and eventually will explain that these two constructions will be analyzed with the same tree diagrams.

\section{The similarity between locative constructions and dative constructions}

According to Larson(1988), dative constructions can deduct double object constructions through the process called dative shift, and also can be called underlying structure of double object constructions. The surface structure of the two constructions consist of $\mathrm{DP}($ determiner phrase) $+\mathrm{PP}$ (prepositional phrase). In addition, in semantic aspect, indirect object is assigned Goal argument, and direct object is assigned Theme argument. Below there are some common examples of these two constructions.

(1) a. He gave flowers to Liz.

b. He brought some cakes to them.

a. He loaded the hay onto the wagon.

b. Jack sprayed paint on the wall. (Lee 2014:560)

What the two construction have in common is that both are identical formally. Also, considering one more thing, those constructions all can form new forms by switching the location between goal argument and theme argument. For instance, in case of dative constructions, double object constructions like (3) below can be built by changing the location of "flowers" (theme argument) for the location of "Liz" (goal argument) in (la). Likewise, in case of locative constructions, the structure like (4) can be formed through "Locative Alternation", which change the site between the theme argument ("the hay") and goal argument ("the wagon") in (2a).

a. He gave Liz flowers.

b. He brought them some cakes.

a. He loaded the wagon with the hay.

b. Jack sprayed the wall with paint. (Lee 2014:560)

There is a difference that each constructions' surface form has not changed, though. For example, in dative constructions, the surface structure has changed into DP+DP while in locative constructions, the structure is the same as before applying the locative alternation. Furthermore, according to Hallman(2015), when the purpose clause is inserted after dative constructions, the PRO in the purpose clause corresponds to indirect object and the zero-element "e" in the purpose clause corresponds to direct object. But, in case of locative constructions, there is no corresponding phenomenons like dative constructions. 
(5) a. Mary gave a puppyj to Johni [PROi to play with ej].

b. Mary sent a manuscriptj to Johni [PROi to read ej].

(Hallman 2015:392)

(6) a. *Mary put the childj on the horsei [PROi to carry ej].

b *Mary led the horsej to Johni [PROi to feed ej].

(Hallman 2015:393)

Given those aspects above, it is likely that the two constructions are different constructions. However, there are some problems about Hallman's opinion. That is because not only dative constructions or double object constructions , PRO is in coreference with goal argument and the zero-element "e" is in coreference with theme argument when the purpose clause is inserted after those constructions. In constructions which are using Secondary Predicate, the same coreference relation mentioned above is established.

(7) a. I gave Maryi the meatj raw.

(Lee 2013:261)

b. I gave Maryi the meatj raw [PROi to eat ej].

Moreover, in double object constructions like below, there is not the same coreference relation presented above.

(8) a. *The lighting here gives mei a headachej

(Bruening 2010:288)

b. * Mary gave Johni a black eyej.

(Larson 1988:376)

c. *The lighting here gives mei a headachej [PROi to suffer ej].

d. * Mary gave Johni a black eyej [PROi to get ej].

Considering (7-8) examples, there is a problem about the way Hallman demonstrated to distinguish dative and double object constructions from locative constructions. Thus, with his argument, there is no reason to argue that dative constructions and locative constructions are different constructions. As the examples below show, not all locative constructions can be converted into (4a-b) structure just as not all dative constructions can be turned into double object constructions.

(9) a. John donates a puppy to Mary.

b. *John donates Mary a puppy.

(10) a. John pushes a cart to San Francisco.

b. *John pushes San Francisco with a cart. (Lee 2014:560)

That is, not all verbs can allow the location change between them argument and goal argument in each constructions. In addition, some verbs allow only dative constructions or double object constructions, and even both constructions. Given this aspect, there is a similarity between dative constructions and locative constructions.

(11) a. I gave Mary some coins.

b. I gave some coins to Mary.

c. I convey some coins to Mary.

d. *I convey Mary some coins.

e. I ask Mary some coins.

f. *I ask some coins to Mary.

(12) a. I loaded the hay onto the wagon.

b. I loaded the wagon with hay.

c. I poured milk into her glass.

d. *I poured her glass with milk.

e. I coated the cake with lemon icing.

f. *I coated lemon icing onto the cake. 
As showed above, there is a similarity between those constructions in light of the fact that not all ,only some, verbs allow each constructions. Furthermore, according to Bruening(2010), there is a asymmetry between dative constructions and double object constructions in terms of the scope of quantifier.

(13) a. I gave a different candy bar to every child. (every > a)

b. I gave a different child every candy bar. (*every > a) (Bruening 2010:292)

As example (13) shows, in case of dative constructions, goal argument has wider scope than theme argument while in double object constructions, theme argument has wider scope than goal argument. In other words, in (14a) below, the interpretation is that the number of medals corresponds to the number of athletes. In contrast, in (15a) below, the interpretation is that all the medals is given to one athlete. In the same manner, there is the same asymmetry in scope mentioned above in locative constructions.

(14) a. I presented a different medal to every track and field athlete. (every > a)

b. I loaded a different pile of boxes on every tractor-trailer rig. (every $>$ a)

(15) a. I presented a different track and field athlete with every medal. (*every $>$ a)

b. I loaded a different tractor-trailer rig with every pile of boxes. (*every $>$ a)

(Bruening 2010:295)

All these things considered, it is found that dative constructions and locative constructions are similar. it is also found out that with-structure in $(4 a-b)$ converted through locative alternation is similar to double object constructions. Therefore, the structure of the dative constructions and locative constructions is likely to be analyzed alike. Hallman(2015) analyzed the dative constructions with "Cause X to have Y' method. Also, Hallman(2015) analyzed the locative constructions with "Cause X to be Y" method.

There is a little difference, but the basic structure is similar to each other. I will accept Hallman's structure but don't accept the opinion that locative constructions and dative constructions are different constructions. Moreover, through this analysis, the economy of language will be come true. Further other constructions will be able to be analyzed with this structure.

\section{Conclusion}

From the similarity of dative constructions and locative constructions appearing superficially to semantic and syntactic feature, we examined that the two constructions are similar and through this it is likely that those constructions are the same constructions. Furthermore, it is found out that with-structure in (4a-b) converted through locative alternation is similar to double object constructions. There is a difference in surface structure, though. That is, double object constructions consist of DP+DP while with-structure in (4a-b) is composed of $\mathrm{DP}+\mathrm{PP}$ like dative constructions. If also these two constructions can be seen the same constructions, the economy principle of language will be fulfilled.

\section{Reference}

[1] Lee, Wonbin. 2013. Some Notes on Double Object Constructions in English. The New Korean Journal of English Language and Literature 55.1, 255-272

https://doi.org/10.25151/nkje.2013.55.1.012

[2] Lee, YeonWha. 2014. Locative Alternation and Theme-Goal Asymmetry. The Journal of Studies in language 30.3, 559-579

[3] Shin, Heung Taek. 2015. A Study of the Semantic and Syntactic Differences between the Double Object Construction and the Prepositional Dative Construction in English. doctorate thesis. Pusan National University

[4] Larson, Richard. 1988. On the Double Object Construction. Linguistic Inquiry vol 19(3), 335-391

[5] Hallman, Peter. 2015. Syntactic Neutralization in Double Object Constructions. Linguistic Inquiry 46(3), 389-424 https://doi.org/10.1162/LING_a_00187

[6] Levin, Beth. 2006. English Object Alternations: A Unified Account. Unpublished ms,

[7] Harley, Heidi, and Hyun Kyoung Jung. 2015. In Support of the PHAVE Analysis of the Double Object Construction. Linguistic Inquiry 46(4), 703-730 https://doi.org/10.1162/LING_a_00198

[8] Bruening, Benjamin. 2010. Double Obejct Constructions Disguised as Prepositional Datives. Linguistic Inquiry 41(2), 287-305

https://doi.org/10.1162/ling.2010.41.2.287 